\title{
Sodium tungstate alleviates biomechanical properties of diabetic rat femur via modulation of oxidative stress
}

\author{
Baris O. Donmez ${ }^{1}$, Nihal Ozturk ${ }^{2}$, Mehmet Sarikanat ${ }^{3}$, Nurettin Oguz $^{4}$, Ramazan Sari ${ }^{5}$ \\ and Semir Ozdemir ${ }^{2}$ \\ ${ }^{1}$ Department of Nutrition and Dietetics, School of Health, Akdeniz University, 07070, Antalya, Turkey \\ ${ }^{2}$ Department of Biophysics, Faculty of Medicine, Akdeniz University, 07070, Antalya, Turkey \\ ${ }^{3}$ Department of Mechanical Engineering, Faculty of Engineering, Ege University, 35100, Izmir, Turkey \\ ${ }^{4}$ Department of Anatomy, Faculty of Medicine, Akdeniz University, 07070, Antalya, Turkey \\ ${ }^{5}$ Department of Internal Medicine, Faculty of Medicine, Akdeniz University, 07070, Antalya, Turkey
}

\begin{abstract}
Diabetes mellitus leads to bone disorders such as osteopenia and osteoporosis that can increase fracture risk. On the other hand, sodium tungstate is an inorganic compound which exerts anti-diabetic activity in experimental studies due to its suggested insulin-mimetic or antioxidant activity. Therefore this study was designed to investigate the effect of tungstate on bone quality in diabetic rat femurs. The rats were divided into four groups: Control (C), tungstate-treated control (C+Tung), diabetes (STZ-D) and tungstate-treated diabetes (STZ-D+Tung). Diabetes mellitus was induced by single injection of streptozotocin $(50 \mathrm{mg} / \mathrm{kg}$ ). The treated rats received $150 \mathrm{mg} / \mathrm{kg} / \mathrm{day}$ of sodium tungstate for 12 weeks. Sodium tungstate achieved a little (17\%) but significant reduction on blood glucose levels, while it didn't recover the reduced body weights of diabetic rats. In addition, impaired bone mechanical quality was reversed, despite the unchanged mineral density. Sodium tungstate administration significantly lowered the 2-thiobarbituric acid reactive substances and restored the activity of tissue antioxidant enzymes such as glutathione peroxidase, catalase and superoxide dismutase in diabetic rats. On the other hand, glutathione levels didn't change in either case. These findings indicate that tungstate can improve the reduced mechanical quality of diabetic rat femurs due probably to reduction of reactive oxygen species and modulation of antioxidant enzymes as well as reduction in blood glucose levels.
\end{abstract}

Key words: Diabetic osteopenia - Sodium tungstate - Oxidative stress - Antioxidants - Bone quality - Mechanical strength

\section{Introduction}

Diabetes mellitus is a systemic disease which causes many complications such as nephropathy, neuropathy, retinopathy and osteopenia (Hamada et al. 2007). Diabetic osteopenia is manifested by increase in bone fracture (Bouillon 1991; Forsen et al. 1999) and a delay in healing of fractures (Cozen 1972; Herskind et al. 1992) and thus affects the quality of life. Although many human and experimental studies on the complications of diabetes mellitus have demonstrated

Correspondence to: Semir Ozdemir, Department of Biophysics, Faculty of Medicine, Akdeniz University, 07070, Antalya, Turkey E-mail: osemir@akdeniz.edu.tr extensive alterations in bone and mineral metabolism (Seino and Ishida 1995), the mechanisms responsible for diabetic osteopenia have not been clearly identified.

Many defects associated with diabetes, such as oxidative stress, hyperglycemia and body weight loss are suggested to be involved in pathogenesis of diabetic osteopenia. Among them, oxidative stress may be the prominent one, since it is known to induce cellular dysfunction in a wide variety of cell types including osteoblasts and osteoclasts (Hamada et al. 2007). Concerning bone metabolism, many studies have reported that oxidative stress inhibits osteoblastic differentiation (Mody et al. 2001; Bai et al. 2004; Hamada et al. 2007) and leads to osteoblast insults and apoptotic cell death (Chen et al. 2005; Fatokun et al. 
2006; Hamada et al. 2007). Thus increased oxidative stress and the reduced activity/expression of counterbalancing antioxidant enzymes may be related to the pathogenesis of diabetic osteopenia.

In recent years, several inorganic elements have been described that mimic the effects of insulin or increase insulin action (Barbera et al. 1994, 2001; Harati and Ani 2004; Gao et al. 2006; Partida-Hernandez et al. 2006; Trumbo and Ellwood 2006; Vasudevan and McNeill 2007; Heidari et al. 2008). Of these elements, sodium tungstate $\left(\mathrm{Na}_{2} \mathrm{WO}_{4}\right)$ which chemically resembles vanadium was shown to have antidiabetic activity in experimental studies based on its suggested insulinomimetic or antioxidant activity (Barbera et al. 1994, 2001; Munoz et al. 2001; Aydemir et al. 2012). Oral administration of sodium tungstate has been reported to normalize glycemia in many animal models of diabetes (Barbera et al. 1994, 1997, 2001; Munoz et al. 2001). Furthermore, it also increases the total amount and translocation of GLUT4 transporter in muscle (Giron et al. 2003) and restores the hepatic metabolism of glucose in streptozotocine(STZ)-treated rats (Rodriguez-Hernandez et al. 2012). Stimulation of insulin secretion (RodriguezGallardo et al. 2000) and regeneration of $\beta$-cell population (Barbera et al. 1997; Rodriguez-Hernandez et al. 2012) following tungstate administration was also reported in STZ-induced diabetes. Similar to vanadium, accumulation of tungstate was mainly recognized in bone tissue of mice after long-term oral administration (Guandalini et al. 2011). However, despite the abundance of studies that have been investigated the effects of vanadate compounds on bone tissue (Barrio et al. 1997; Etcheverry et al. 1997; Facchini et al. 2006) the impact of tungstate administration either in healthy or diseased state has not been defined yet.

Growing evidence and our previous results suggest that reactive oxygen species (ROS) play an important role in diabetes-induced abnormalities in various tissues and tungstate can reduce the upregulated oxidative stress parameters probably via restoration of antioxidant defense mechanisms (Hamada et al. 2007, 2009; Nakhaee et al. 2010; Blakytny et al. 2011; Aydemir et al. 2012). However, despite the above studies reporting the influence of tungstate administration on various tissues, there is no information on the effect of tungstate on bone biomechanical properties in diabetic rats. Therefore, we focused on antioxidant capacity and beneficial effects of tungstate in bone tissue of diabetic rats. In the present study, we investigated the effects of tungstate on bone mechanics and evaluated its potential antioxidant activity in prevention of diabetic osteopenia. Our results showed that tungstate can improve impaired bone properties in diabetic rats via reduction of oxidative stress and restoration of the activity of the endogenous antioxidant enzymes including glutathione peroxidase (GPx), superoxide dismutase (SOD) and catalase (CAT).

\section{Materials and Methods}

\section{Animals}

Eighty male Wistar rats, 90 days old and 250-300 g body weight (Akdeniz University, Faculty of Medicine, Animal Laboratory, Antalya, Turkey) were used for the present study. They were maintained in a well-ventilated controlled room on a 12 -h light and 12 -h dark cycle at $22^{\circ} \mathrm{C}$ room temperature. The animals had access to standard laboratory chow and water ad libitum. Experimental procedures were approved and carried out in accordance with Akdeniz University Animal Care and Use Committee's guidelines. They were divided into four groups: Control (C; $n=20)$, tungstatetreated control (C+Tung; $n=20)$, diabetes (STZ-D; $n=20$ ) and tungstate-treated diabetes (STZ-D+Tung; $n=20$ ).

Diabetes was induced by intraperitoneal injection of STZ (Applichem GmbH, Germany) at the doze of $50 \mathrm{mg} / \mathrm{kg}$ body weight (STZ-D and STZ-D+Tung). After injection, blood glucose levels were monitored one week later by Accu-check glucometer (Roche Diagnostic, Turkey). Only rats with blood glucose levels higher than $300 \mathrm{mg} / \mathrm{dl}$ were enrolled in the study to ensure diabetic state.

Tungstate was dissolved in water and administered via oral gavages $(150 \mathrm{mg} / \mathrm{kg} /$ day) during 12 weeks (C+Tung and STZ-D+Tung). The same amount of vehicle was administered to the age-matched control groups (C and STZ-D groups) for the same period. All animals were sacrificed by overdose of urethane anesthesia at the end of $12^{\text {th }}$ week. Femurs were collected for biomechanical evaluations, bone mineral density (BMD) measurements and oxidative stress measurement.

\section{Measurement of BMD}

BMD of the excised femurs was determined by DEXA (Hologic Discovery QDR, 2009, USA) using a dedicated small animal software. Before the measurements, the instrument was calibrated by means of a Hologic phantom. After BMD measurements were performed on all bones, they were separated into two parts for biomechanical and biochemical experiments, respectively.

\section{Preparation of bone for biomechanical test}

The biomechanical properties of bone were measured using tensile test and ten femurs were used for each group. Test was performed with a computerized Lloyd testing machine (Lloyd LR5K, West Sussex, UK) and analyzed by Lloyd software. The biomechanical test was conducted by a $5-\mathrm{kN}$ load cell and at a crosshead speed of $2 \mathrm{~mm} / \mathrm{min}$ at room temperature. Following removal of the soft tissues around 
the femurs, they were mounted vertically in the machine with the use of acrylic cement. During test, isotonic solution was regularly applied to prevent drying of the bones. Tensile test was applied until fracture of bones. The bones that dislodged from the acrylic cement during the mechanical test excluded from the experiments.

\section{Calculation of biomechanical data}

Typical force-displacement and stress-strain curves obtained from the tensile test were analyzed as described before (Donmez et al. 2012). By this way ultimate tensile load, ultimate tensile strength, strain, stiffness, tensile modulus (Young's modulus) was measured. After fracture, the thinnest region of the femoral shaft was cut horizontally and pictured. Cortical surface areas were calculated from the pictures as square millimeter by using Image-J Software (U. S. National Institutes of Health, 2008, Bethesda, Maryland, USA).

Stiffness $(K, \mathrm{~N} / \mathrm{mm})$ is determined from the slope of the elastic region of the load-displacement curve which represents the extrinsic stiffness by means of the following equation; $K=\Delta P / \Delta u$. The ultimate stress was calculated from the equation: $\sigma=P / A$ where $\sigma$ is the ultimate stress $(\mathrm{MPa}), P$ is the failure load $(\mathrm{N})$ and $A$ is the cortical area $\left(\mathrm{mm}^{2}\right)$.

The Tensile or Young's modulus is a measure of the intrinsic stiffness of the material. The tensile modulus $(E)$ can be simply calculated from the slope of stress-strain curve within the elastic region. Furthermore the tensile modulus $(\mathrm{MPa})$ was then calculated as follows: $E=\Delta \sigma / \Delta \varepsilon$ where $\varepsilon$ is the strain. The strain (\% displacement) was obtained by the equation: $\varepsilon=\Delta L / L_{0}$, where $\Delta L$ is the change in the length and $L_{0}$ is the original length (Donmez et al. 2012).

\section{Biochemical assay}

One of each femora pair was used for mechanical test while the other one were pulverized in liquid nitrogen for biochemical assays. The weighed pulverous of bones transferred equally into appropriate assay buffer $(0.2 \mathrm{mg} / \mathrm{ml})$ and homogenized by PRO200 Homogenizer (PRO Scientific Inc., Connecticut, USA).

\section{2-thiobarbituric acid reactive substances (TBARS)}

TBARS levels were measured by fluorometric analysis using 1,1,3,3-tetramethoxypropane as a standard (Wasowicz et al. 1993). Briefly, tissue samples $(50 \mu \mathrm{l})$ were placed into a tube containing $1 \mathrm{ml}$ of distilled water. One milliliter of a solution containing $29 \mathrm{mmol} / \mathrm{l} 2$-thiobarbituric acid (TBA) in acetic acid $(8.75 \mathrm{~mol} / \mathrm{l})$ was added to the samples then placed in a water bath at $95-100^{\circ} \mathrm{C}$ for $1 \mathrm{~h}$. After the samples cooled, $25 \mu \mathrm{l}$ of $5 \mathrm{~mol} / \mathrm{l}$ hydrochloric acid $(\mathrm{HCl})$ was added to the mixture. Reaction product was extracted from the samples with $3.5 \mathrm{ml}$ of n-butanol, vortexed, than centrifuged at 3000 $\times g$ for $10 \mathrm{~min}$. The butanol phase containing the extracted reaction product was separated and fluorescence was measured by spectrophotometry (Perkin Elmer Luminescence spectrometer, LS50B) using wavelengths of $525 \mathrm{~nm}$ for excitation and $547 \mathrm{~nm}$ for emission.

\section{SOD Activity}

The femora were homogenized in cold $20 \mathrm{mM}$ HEPES buffer, pH 7.2, containing $1 \mathrm{mM}$ EDTA. Then samples were centrifuged at $1,500 \times g$ for $5 \mathrm{~min}$ at $4^{\circ} \mathrm{C}$ and supernatants were kept at $-80^{\circ} \mathrm{C}$ until assayed. Superoxide activity was measured using a SOD activity assay kit (Cayman-706002) (Malstrom et al. 1975). One unit of SOD activity was defined as the amount of enzyme needed to exhibit 50\% dismutation of superoxide radical.

\section{CAT activity}

The femora were homogenized in cold $50 \mathrm{mM}$ potassium phosphate, pH 7.0, containing $1 \mathrm{mM}$ EDTA. Tissue homogenates were centrifuged at $10,000 \times g$ for $15 \mathrm{~min}$ at $4^{\circ} \mathrm{C}$. CAT activity was measured using a CAT activity assay kit (Cayman-707002) (Johansson and Borg 1988). The method is based on the reaction of the enzyme with methanol in the presence of $\mathrm{H}_{2} \mathrm{O}_{2}$. The formaldehyde produced is measured spectrophotometrically with purpald (4-amino-3-hydrazino-5-marcapto-1,2,4- traizole) as the chromogen. One unit of enzyme activity was defined as the amount of enzyme that caused the formation of $1 \mu \mathrm{mol}$ formaldehyde per minute at $25^{\circ} \mathrm{C}$.

\section{GPx activity}

The femora were homogenized in cold $50 \mathrm{mM}$ Tris- $\mathrm{HCl}$ buffer at pH 7.5, containing $1 \mathrm{mM}$ EDTA. Tissue homogenates were centrifuged at $10,000 \times g$ for $15 \mathrm{~min}$ at $4^{\circ} \mathrm{C}$. GPx was measured using a GPx activity assay kit (Cayman707002) (Johansson and Borg 1988). The GPx activity assay kit measures enzyme activity indirectly by a coupled reaction with glutathione reductase (GR). The oxidation of NADPH to NADP is accompanied by a decrease in absorbance at $340 \mathrm{~nm}$. Absorbance kinetics was assessed spectrophotometrically at $340 \mathrm{~nm}$ by using the NADPH extinction coefficient of $0.00622 \mu \mathrm{M}^{-1} \cdot \mathrm{cm}^{-1}$. One unit of enzyme activity was defined as the amount of enzyme that caused the oxidation of $\mu \mathrm{mol} \mathrm{NADPH}$ to NADP per minute at $25^{\circ} \mathrm{C}$.

\section{Glutathione (GSH) content}

GSH was measured by a commercially available GSH assay kit (Cayman Chemical Ann Arbor, MI). Supernatants were 
deproteinated in 10\% metaphosphoric acid (Sigma Aldrich, Steinheim, Switzerland). The GSSG was reduced to GSH by GSH reductase in the assay cocktail of the kit containing 5,5'-dithiobis-2-nitrobenzoic acid (DTNB), glucose-6phosphate de-hydrogenase, GSH reductase, nicotinamide adenine dinucleotide phosphate $\left(\mathrm{NADP}^{+}\right)$and glucose-6phosphate. The sulfhydryl group of GSH reacts with DTNB to give a yellow colored 5-thio-2- nitrobenzoic acid (TNB) which is measured at $405 \mathrm{~nm}$ wavelength.

\section{Statistical analysis}

One-way ANOVA was used for the first step analysis of the data. Then, multiple comparisons of the relevant groups were performed by posthoc Tukey test. The difference was accepted significant when $p<0.05$.

\section{Results}

\section{Body weight and blood glucose levels}

The blood glucose level of group STZ-D was significantly higher when compared to group $\mathrm{C}$ at the end of the third month $(p<0.05)$. Despite a significant reduction in blood glucose levels of STZ-D+Tung group after treatment, they were higher than control levels $(p<0.01)$. However, the body weight of group STZ-D was significantly decreased with respect to group $C$ rats at the end of the experimental period $(p<0.05)$ and tungstate did not prevent the weight loss of diabetic rats $(p>0.05)$ (Table 1$)$.

\section{Biomechanical findings and BMD}

According to our results, mineral density was decreased in STZ-D group with respect to control values $(p<0.05)$. However, tungstate did not reveal any change in STZ$\mathrm{D}+$ Tung group values (Figure 1). Tensile strength and strain values of group STZ-D was lower than group C, but despite a striking and significant restoration of tensile strength was achieved in STZ-D+Tung group femurs $(p<0.05)$, the reversal of strain values didn't reach a significant level (Figure 1). A lower maximum load was detected in group STZ-D femurs and tungstate administration reversed this reduction. In conclusion, tungstate administration to the diabetic rats reversed the decreased femur strength, increased the maximum load and improved the strain values. However, Young modulus and stiffness were not significantly changed between experimental groups (Figure 1). Additionally, there were no significant differences in mechanical properties and $\mathrm{BMD}$ values of treated control animals with respect to untreated controls.

\section{Biochemical parameters of bone}

Diabetes induction revealed a highly significant increase in TBARS values of rat bones and administration of tungstate reversed this increment $(p<0.05)$. However, GPx activity was decreased markedly in group STZ-D femurs with respect to control values, despite a significant elevation in CAT activity. Activities of both enzymes were significantly reversed in STZ-D+Tung group $(p<0.05)$ bones. Neither diabetes-induction nor tungstate administration elicited significant alteration in measured activities of GSH and SOD enzymes $(p>0.05)$ (Figure 2). Unexpectedly, increased TBARS levels and reduced GPx activity were detected in normal rats after tungstate administration, although it didn't induce any change in the other parameters.

\section{Discussion}

In this study we demonstrated that tungstate improved the biomechanical properties of diabetic rat bone significantly. In addition, increased oxidative stress and altered antioxidant enzymatic activities of bone tissue were restored after tungstate administration. Therefore this is the first study to show tungstate exerts beneficial effect on diabetic osteopenia due to its antioxidant activity and suppression of oxidative stress. These findings render the possible use

Table 1. Body weight and glucose levels of experimental groups

\begin{tabular}{lcccc}
\hline \multirow{2}{*}{ Groups } & \multicolumn{2}{c}{ Body weight $(\mathrm{g})$} & \multicolumn{2}{c}{ Glucose levels $(\mathrm{mmol} / \mathrm{l})$} \\
\cline { 2 - 5 } & \multicolumn{1}{c}{ Start } & Final & Start & Final \\
\hline C & $323 \pm 30$ & $387 \pm 37$ & $7.06 \pm 0.96$ & $6.41 \pm 0.51$ \\
C+Tung & $321 \pm 26$ & $379 \pm 44$ & $6.75 \pm 1.54$ & $6.74 \pm 0.83$ \\
STZ-D & $312 \pm 25$ & $258 \pm 44^{*, \#}$ & $29.42 \pm 3.95^{\#}$ & $28.19 \pm 4.19^{\#}$ \\
STZ-D+Tung & $319 \pm 35$ & $244 \pm 62^{*, \#}$ & $25.64 \pm 3.76^{\#}$ & $21.35 \pm 7.40^{*, \#, \dagger}$ \\
\hline
\end{tabular}

All values are given as the mean \pm standard deviation (SD). ${ }^{*} p<0.05$ initial $v s$. final values. ${ }^{\#} p<0.05 v s$. C group. ${ }^{\dagger} p<0.05 v$ s. STZ-D group ( $n=20$ for all groups). C, control; C+Tung, tungstate-treated control; STZ-D, diabetes; STZ-D+Tung, tungstate-treated diabetes. 
A

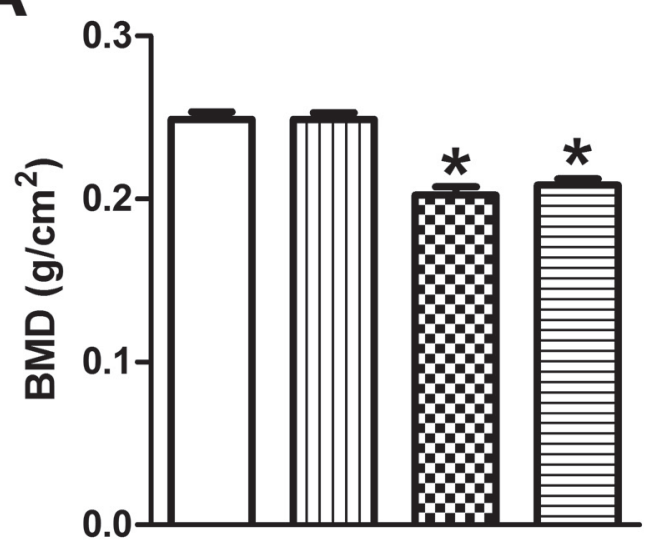

C

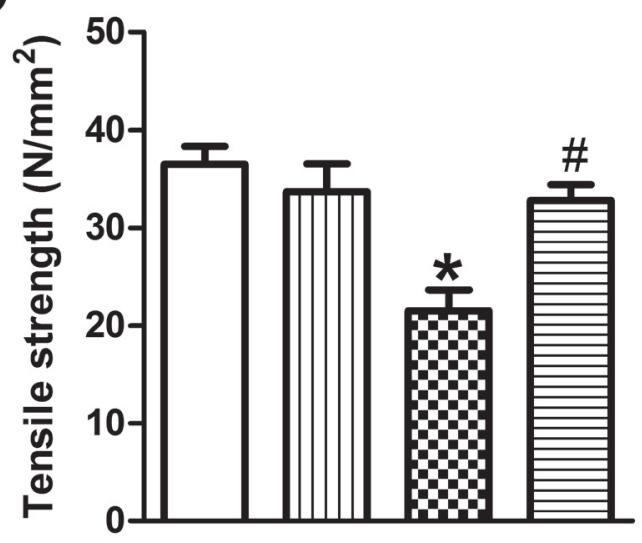

E

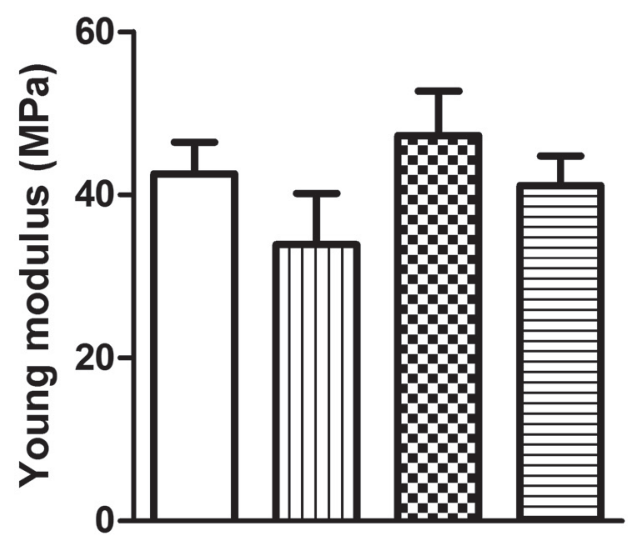

B

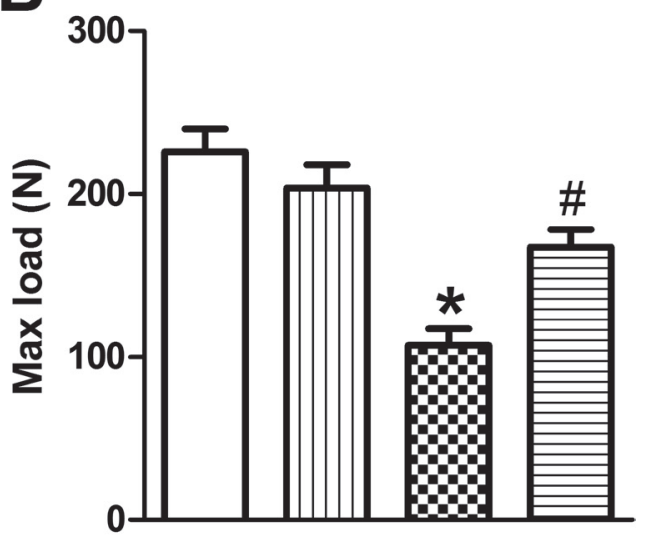

D
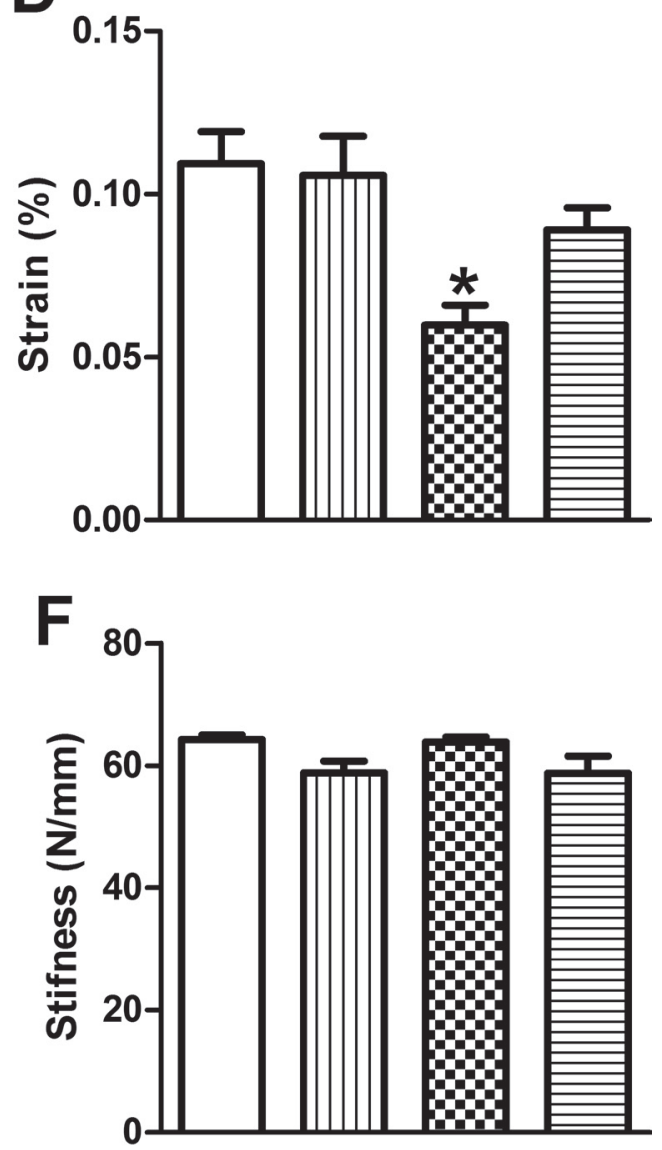

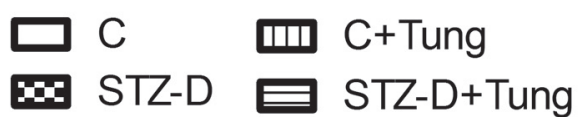

Figure 1. Effects of tungstate on biomechanical parameters in diabetic rat femur. A. BMD was decreased in streptozotocin-induced diabetes (STZ-D) group with respect to control $(\mathrm{C})$ group $(p<0.05)$ but tungstate treatment did not reveal any change in STZ-D+Tung group values $(p>0.05)$. B, C, D. Tungstate treatment significantly improved the maximum load and the femur strength in diabetic rats' femur. E. F. Young modulus and stiffness of STZ-D group were not different between groups $(p>0.05)$. Data are represented as mean \pm SEM. ${ }^{*} p<0.05$ vs. C; ${ }^{\#} p<0.05$ vs. STZ-D $(n=14-19)$. 
A

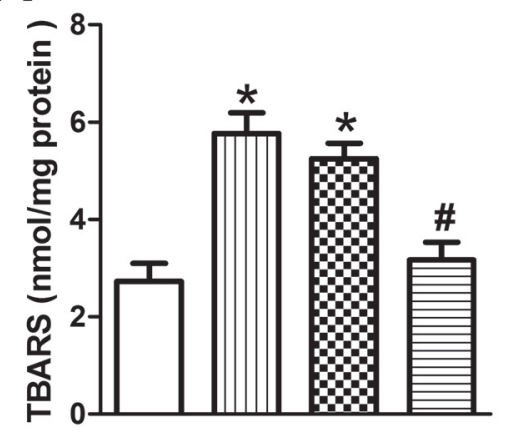

D

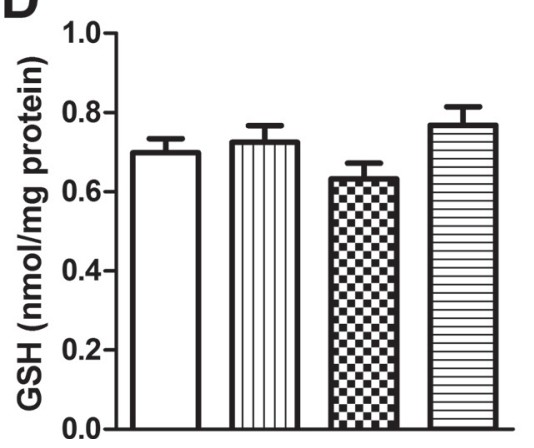

B

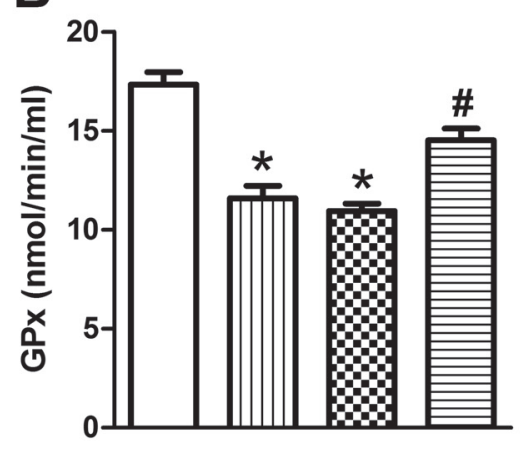

E

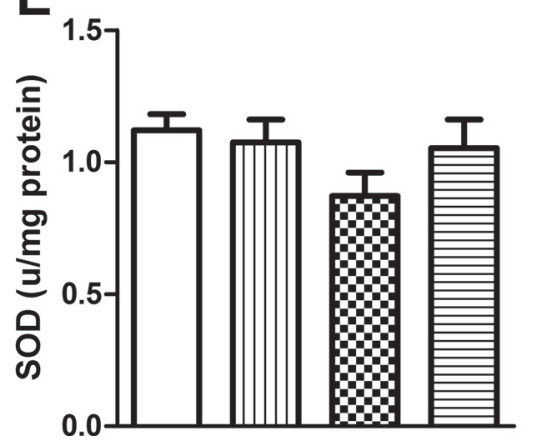

C
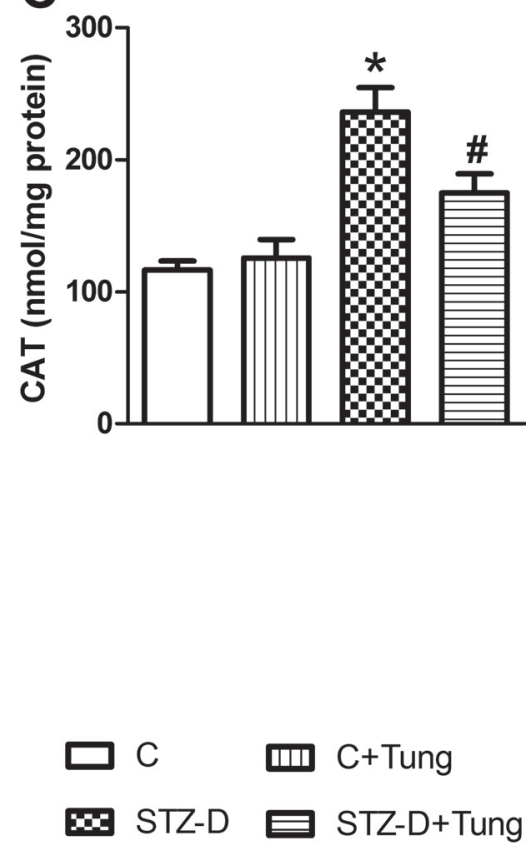

Figure 2. Tungstate treatment reduced diabetes-induced oxidative stress and ameliorated antioxidant enzyme activities. TBARS (A), GPx (B), CAT (C), GSH (D) and SOD (E). Increased TBARS values were measured in diabetic rat bones and tungstate treatment reversed this increment significantly $(p<0.05)$ but GPx activity was decreased in streptozotocin-induced diabetes (STZ-D) group femurs, in spite of a significant elevation in CAT activity $(p<0.05)$. Data are represented as mean \pm SEM. ${ }^{*} p<0.05 v s$. C; ${ }^{\#} p<0.05 v s$. STZ-D $(n=10)$.

of this compound as a therapeutic agent for alleviation of diabetic osteopenia.

Diabetes mellitus leads to musculoskeletal abnormalities such as diminished bone formation, delayed bone healing, osteopenia and osteoporosis (Bouillon 1991; Herskind et al. 1992; Hamada et al. 2007). Lowered bone turnover associated with alteration in bone mass and biomechanical integrity of bone has been shown in experimental animal models of diabetes (Reddy et al. 2001; Follak et al. 2004, 2005; Facchini et al. 2006; Kidder et al. 2009). As a result of this decreased bone strength, energy absorption capacity and mineral content have been characterized in diabetic rats' femur (Verhaeghe et al. 1994). During mechanical test such as bending, torsion and compression diabetes caused a decrease in bending strength, compression strength and tensile strength value of bone (Reddy et al. 2001; Facchini et al. 2006; Silva et al. 2009). Consistent with previous studies diabetic osteopenia was successfully induced by single dose injection of STZ and characterized by a sharp increase in blood glucose levels, reduced BMD and decreased bone biomechanical quality (Reddy et al. 2001; Facchini et al. 2006;
Liang et al. 2011). In the light of our biomechanical results, bones from type 1 diabetic animals were less stiff and strong than control animals. Despite the value of tensile strength and strain were decreased in STZ-D group with respect to C group animals, tungstate administration improved these properties of diabetic rats' femurs, even though it didn't reverse the reduced $\mathrm{BMD}$. This may be due to the fact that bone strength is relevant not only to bone mineralization but also to bone quality which is dependent primarily on bone turnover. Consistently, previous reports and the findings of the present study infer lowered bone turnover and thus impaired bone remodeling in diabetic osteopenia (Hamada et al. 2007, 2009; Blakytny et al. 2011). Therefore it is likely to suggest that this improved quality of femurs in tungstatetreated diabetic rats may stem from the alleviated bone turnover rather than augmentation of mineral content.

Tungstate administration has been shown to exert antidiabetic effects in many experimental studies. Furthermore, it is proposed as an efficient oral anti-diabetic agent since it potentiates insulin effects in adipocytes (Goto and Kida 1995; Li 1995), stimulates insulin release in pancreas (Silves- 
tre et al. 2005) and favors $\beta$-cell regeneration (FernandezAlvarez et al. 2004). Tungstate was capable of lowering the blood glucose level only to some extent, since it was still substantially higher than control's even at the end of $3^{\text {rd }}$ month. Similarly body weight loss was apparent throughout the experimental period and it wasn't relieved by tungstate administration. Contrary to the previous reports we didn't observe such a considerable recovery in blood glucose levels that may explain the whole findings of this study and confirm the attributed anti-diabetic function. This discrepancy may stem from the ingested quantity of sodium tungstate which is generally higher in previous reports than we used in our study. We preferred relatively lower dose of sodium tungstate, because when high levels are administered the potential side effects should be considered. In summary, regardless of these contradictions, we clearly described that hyperglycemia was capable of leading the incidence of osteopenia in type 1 diabetic rats. Moreover, although the role of this partially reduced blood glucose in improvement of bone quality cannot be excluded at all, the current findings imply that the benefit obtained by tungstate administration may have another aspect apart from reduction in blood glucose levels.

Although it is known that diabetes affects bone as well as many other tissues, the exact mechanism is not clear, yet. One of the possible underlying processes is high glucose which results in excessive formation of ROS. This oxidative stress which is induced by increased blood glucose in diabetic conditions is known to induce cellular dysfunction in a wide variety of cell types including bone cells (Hamada et al. 2007, 2009). Zhen et al. (2010) reported that persistent high glucose level is capable of influencing osteoblast differentiation, impairing bone formation and inhibiting bone mineralization possibly via stimulation of oxidative stress production which has been suggested to be an important contributing factor for the incidence of diabetic osteopenia (Bai et al. 2004; King and Loeken 2004; Hamada et al. 2009; Liang et al. 2011). Consistently, many experimental studies, including our previous reports have demonstrated extensive increase in ROS in diabetic animal tissues (Ozdemir et al. 2009; Liang et al. 2011; Aydemir et al. 2012). ROS comprises an array of chemical entities such as oxygen free radicals, hydrogen peroxide, nitric oxide (NO) and peroxynitrite which are produced at low levels even in physiological conditions and scavenged by endogenous antioxidant systems such as GPx, GSH, SOD, and CAT. But when the balance between those two systems shifted due to increased free radical generation and/or downregulated defence mechanisms ROS can cause severe damage to DNA, proteins, and lipids (Hamada et al. 2009). We also measured a striking increase in TBARS levels of diabetic rat femurs which were restored by tungstate and thereby proved the potential antioxidant impact of this agent.
The altered activities of endogenous antioxidants in the diabetic rats reinforce our hypothesis that suggests oxidative stress is one of the major factors behind the low bone quality in these animals. Interestingly, we measured a striking decrease in GPx along with a significant increase in CAT. Up to date divergent observations have been seen for antioxidant enzymes in diabetes and the reasons for these discrepancies have not been addressed unequivocally. The tissue type under consideration, the expression level of the studied enzyme and the temporal changes in enzyme's activity may be the possible reasons underlying these variations. Consistent with this the expression of CAT in bone tissue was found to be extremely low with respect to GPx (Lean et al. 2005). On the other hand, the preferential enzymatic pathway undertaken by cells for detoxification of ROS can be an alternative explanation. Under normal conditions, $\mathrm{H}_{2} \mathrm{O}_{2}$ is derived by dismutation of superoxide radical and detoxified by either CAT and/or GPx. At low concentration of $\mathrm{H}_{2} \mathrm{O}_{2} \mathrm{GPx}$ is the predominant pathway whereas catalase appears to be the preferred pathway for detoxification at higher amounts of $\mathrm{H}_{2} \mathrm{O}_{2}$ (Pieper et al. 1995; Baud et al. 2004). This is due probably to extremely high $\mathrm{Km}$ of CAT than the $\mathrm{Km}$ of GPx which means CAT is particularly important when the clearance of $\mathrm{H}_{2} \mathrm{O}_{2}$ in high concentrations is required (Baud et al. 2004). In summary at early stages of diabetes GPx can be the scavenger enzyme preferentially, but lately when oxidative stress increased progressively it might inhibit GPx and activate CAT.

The increased TBARS levels along with decreased GPx activity in control animals after tungstate administration imply a pro-oxidant activity for tungstate in normal conditions as suggested by Sachdeva and Flora (2014). This infers that the effect of tungstate in diseased and normal conditions can be different, although we don't know the reason of this discrepancy explicitly. However human and animal studies revealed that diabetes causes significant decrease in selenium which is located at the catalytic site of the enzyme GPx and its deficiency is associated mainly with decreased GPx activity (Kljai and Runje 2001; Gür 2004). Therefore it is likely to speculate that tungstate may substitute selenium and restores GPx function in diabetic rats while it facilitate free radical production in normal condition due to its excessive level. The demonstration of the exact mechanism of side-effects of tungstate particularly in healthy animals is an important point and further studies should unveil the cover of this issue.

Diabetes induced only a partial and insignificant decrease in SOD and GSH activities and tungstate administration reversed these decrements back to the control levels. Despite the contradictory results that present decreased or unchanged SOD activities (Pieper et al. 1995; Liang et al. 2011), the lack of significant difference can be attributed to the greater rate constant of SOD for dismutation of superoxide radical to form $\mathrm{H}_{2} \mathrm{O}_{2}$ than the subsequent reaction which 
degrades $\mathrm{H}_{2} \mathrm{O}_{2}$ (Pieper et al. 1995). Moreover the tissue used for assessment of oxidative stress can be the reason of these differences in enzymes' activity. It is important to note that although the assessment of systemic oxidative stress products and antioxidant enzymes' status is so common in previous reports (Hamada et al. 2007, 2009; Liang et al. 2011) the local measurements of those parameters such as TBARS, GSH, GPx, SOD and CAT are rarely performed. In this manner, our study provides direct evidence about the intensity of oxidative stress in bone tissue specifically and led us to suggest a causal relationship between increased ROS production and etiology of diabetic osteopenia.

This study clearly shows that tungstate is capable of increasing quality of bone and its resistance to fracture in diabetic rats due probably to mitigated oxidative stress and partially improved glycemic status. Hence, tungstate exerts beneficial effect in diabetic osteopenia owing to its combined antioxidant activity and blood glucose improving capacity.

Acknowledgements. This study was supported by Akdeniz University Scientific Research Coordination Unit grant.

Conflict of interest: The authors have no conflicts.

\section{References}

Aydemir M., Ozturk N., Dogan S., Aslan M., Olgar Y., Ozdemir S. (2012): Sodium tungstate administration ameliorated diabetes-induced electrical and contractile remodeling of rat heart without normalization of hyperglycemia. Biol. Trace Elem. Res. 148, 216-223 http://dx.doi.org/10.1007/s12011-012-9350-8

Bai X. C., Lu D., Bai J., Zheng H., Ke Z. Y., Li X. M., Luo S. Q. (2004): Oxidative stress inhibits osteoblastic differentiation of bone cells by ERK and NF-kappaB. Biochem. Biophys. Res. Commun. 314, 197-207

http://dx.doi.org/10.1016/j.bbrc.2003.12.073

Barbera A., Rodriguez-Gil J. E., Guinovart J. J. (1994): Insulin-like actions of tungstate in diabetic rats. Normalization of hepatic glucose metabolism. J. Biol. Chem. 269, 20047-20053

Barbera A., Fernandez-Alvarez J., Truc A., Gomis R., Guinovart J. J. (1997): Effects of tungstate in neonatally streptozotocininduced diabetic rats: mechanism leading to normalization of glycaemia. Diabetologia 40, 143-149 http://dx.doi.org/10.1007/s001250050655

Barbera A., Gomis R. R., Prats N., Rodriguez-Gil J. E., Domingo M., Gomis R., Guinovart J. J. (2001): Tungstate is an effective antidiabetic agent in streptozotocin-induced diabetic rats: a long-term study. Diabetologia 44, 507-513 http://dx.doi.org/10.1007/s001250100479

Barrio D. A., Braziunas M. D., Etcheverry S. B., Cortizo A. M. (1997): Maltol complexes of vanadium (IV) and (V) regulate in vitro alkaline phosphatase activity and osteoblast-like cell growth. J. Trace Elem. Med. Biol. 11, 110-115 http://dx.doi.org/10.1016/S0946-672X(97)80035-1
Baud O., Greene A. E., Li J., Wang H., Volpe J. J., Rosenberg P. A. (2004): Glutathione peroxidase-catalase cooperativity is required for resistance to hydrogen peroxide by mature rat oligodendrocytes. J. Neurosci. 24, 1531-1540 http://dx.doi.org/10.1523/JNEUROSCI.3989-03.2004

Blakytny R., Spraul M., Jude E. B. (2011): Review: The diabetic bone: a cellular and molecular perspective. Int. J. Low Extrem. Wounds 10, 16-32 http://dx.doi.org/10.1177/1534734611400256

Bouillon R. (1991): Diabetic bone disease. Calcif. Tissue Int. 49, 155-160 http://dx.doi.org/10.1007/BF02556109

Chen R. M., Wu G. J., Chang H. C., Chen J. T., Chen T. F., Lin Y. L., Chen T. L. (2005): 2,6-Diisopropylphenol protects osteoblasts from oxidative stress-induced apoptosis through suppression of caspase-3 activation. Ann. N. Y. Acad. Sci. 1042, 448-459 http://dx.doi.org/10.1196/annals.1338.038

Cozen L. (1972): Does diabetes delay fracture healing? Clin. Orthop. Relat. Res. 82, 134-140 http://dx.doi.org/10.1097/00003086-197201000-00017

Donmez B. O., Ozdemir S., Sarikanat M., Yaras N., Koc P., Demir N., Karayalcin B., Oguz N. (2012): Effect of angiotensin II type 1 receptor blocker on osteoporotic rat femurs. Pharmacol. Rep. 64, 878-888 http://dx.doi.org/10.1016/S1734-1140(12)70882-4

Etcheverry S. B., Crans D. C., Keramidas A. D., Cortizo A. M. (1997): Insulin-mimetic action of vanadium compounds on osteoblast-like cells in culture. Arch. Biochem. Biophys. 338, 7-14 http://dx.doi.org/10.1006/abbi.1996.9778

Facchini D. M., Yuen V. G., Battell M. L., McNeill J. H., Grynpas M. D. (2006): The effects of vanadium treatment on bone in diabetic and non-diabetic rats. Bone 38, 368-377 http://dx.doi.org/10.1016/j.bone.2005.08.015

Fatokun A. A., Stone T. W., Smith R. A. (2006): Hydrogen peroxide-induced oxidative stress in MC3T3-E1 cells: The effects of glutamate and protection by purines. Bone 39, 542-551 http://dx.doi.org/10.1016/j.bone.2006.02.062

Fernandez-Alvarez J., Barbera A., Nadal B., Barcelo-Batllori S., Piquer S., Claret M., Guinovart J. J., Gomis R. (2004): Stable and functional regeneration of pancreatic beta-cell population in nSTZ-rats treated with tungstate. Diabetologia 47, $470-477$ http://dx.doi.org/10.1007/s00125-004-1332-8

Follak N., Kloting I., Wolf E., Merk H. (2004): Improving metabolic control reverses the histomorphometric and biomechanical abnormalities of an experimentally induced bone defect in spontaneously diabetic rats. Calcif. Tissue Int. 74, 551-560 http://dx.doi.org/10.1007/s00223-003-0069-6

Follak N., Kloting I., Merk H. (2005): Influence of diabetic metabolic state on fracture healing in spontaneously diabetic rats. Diabetes Metab. Res. Rev. 21, 288-296 http://dx.doi.org/10.1002/dmrr.537

Forsen L., Meyer H. E., Midthjell K., Edna T. H. (1999): Diabetes mellitus and the incidence of hip fracture: results from the Nord-Trondelag Health Survey. Diabetologia 42, 920-925 http://dx.doi.org/10.1007/s001250051248 
Fujii H., Hamada Y., Fukagawa M. (2008): Bone formation in spontaneously diabetic Torii-newly established model of non-obese type 2 diabetes rats. Bone 42, 372-379 http://dx.doi.org/10.1016/j.bone.2007.10.007

Gao L. H., Liu W. P., Wang B. L., Li L., Xie M. J., Li Y. R., Chen Z. H., Chen X. Z. (2006): Effects of bis(alpha-furancarboxylato)o xovanadium(IV) on non-diabetic and streptozotocin-diabetic rats. Clin. Chim. Acta 368, 173-178 http://dx.doi.org/10.1016/j.cca.2005.12.028

Giron M. D., Caballero J. J., Vargas A. M., Suarez M. D., Guinovart J. J., Salto R. (2003): Modulation of glucose transporters in rat diaphragm by sodium tungstate. FEBS Lett. 542, 84-88 http://dx.doi.org/10.1016/S0014-5793(03)00352-1

Goto Y., Kida K. (1995): Insulin-like action of chromate on glucose transport in isolated rat adipocytes. Jpn. J. Pharmacol. 67, 365-368 http://dx.doi.org/10.1254/jjp.67.365

Guandalini G. S., Zhang L., Fornero E., Centeno J. A., Mokashi V. P., Ortiz P. A., Stockelman M. D., Osterburg A. R., Chapman G. G. (2011): Tissue distribution of tungsten in mice following oral exposure to sodium tungstate. Chem. Res. Toxicol. 24, 488-493 http://dx.doi.org/10.1021/tx200011k

Gür S. (2004): Effects of sodium selenate treatment on altered responses of left and right atria from streptozotocin-induced diabetic rats. J. Cardiovasc. Pharmacol. 44, 9-15 http://dx.doi.org/10.1097/00005344-200407000-00002

Hamada Y., Kitazawa S., Kitazawa R., Fujii H., Kasuga M., Fukagawa M. (2007): Histomorphometric analysis of diabetic osteopenia in streptozotocin-induced diabetic mice: a possible role of oxidative stress. Bone 40, 1408-1414 http://dx.doi.org/10.1016/j.bone.2006.12.057

Hamada Y., Fujii H., Kitazawa R., Yodoi J., Kitazawa S., Fukagawa M. (2009): Thioredoxin-1 overexpression in transgenic mice attenuates streptozotocin-induced diabetic osteopenia: a novel role of oxidative stress and therapeutic implications. Bone 44, 936-941 http://dx.doi.org/10.1016/j.bone.2008.12.011

Harati M., Ani M. (2004): Vanadyl sulfate ameliorates insulin resistance and restores plasma dehydroepiandrosterone-sulfate levels in fructose-fed, insulin-resistant rats. Clin. Biochem. 37, 694-697 http://dx.doi.org/10.1016/j.clinbiochem.2004.01.013

Heidari Z., Mahmoudzadeh-Sagheb H., Moudi B. (2008): A quantitative study of sodium tungstate protective effect on pancreatic beta cells in streptozotocin-induced diabetic rats. Micron 39, 1300-1305 http://dx.doi.org/10.1016/j.micron.2008.02.014

Herskind A. M., Christensen K., Norgaard-Andersen K., Andersen J. F. (1992): Diabetes mellitus and healing of closed fractures. Diabetes Metab. 18, 63-64

Johansson L. H., Borg L. A. (1988): A spectrophotometric method for determination of catalase activity in small tissue samples. Anal. Biochem. 174, 331-336 http://dx.doi.org/10.1016/0003-2697(88)90554-4

Kidder L. S., Chen X., Schmidt A. H., Lew W. D. (2009): Osteogenic protein-1 overcomes inhibition of fracture healing in the diabetic rat: a pilot study. Clin. Orthop. Relat. Res. 467, 3249-3256 http://dx.doi.org/10.1007/s11999-008-0405-2
King G. L., Loeken M. R. (2004): Hyperglycemia-induced oxidative stress in diabetic complications. Histochem. Cell. Biol. 122, 333-338 http://dx.doi.org/10.1007/s00418-004-0678-9

Kljai K., Runje R. (2001): Selenium and glycogen levels in diabetic patients. Biol. Trace Elem. Res. 83, 223-229 http://dx.doi.org/10.1385/BTER:83:3:223

Lean J. M., Jagger C. J., Kirstein B., Fuller K., Chambers T. J. (2005): Hydrogen peroxide is essential for estrogen-deficiency bone loss and osteoclast formation. Endocrinology 146, 728-735 http://dx.doi.org/10.1210/en.2004-1021

Li J., Elberg G., Gefel D., Shechter Y. (1995): Permolybdate and pertungstate--potent stimulators of insulin effects in rat adipocytes: mechanism of action. Biochemistry 34, 6218-6225 http://dx.doi.org/10.1021/bi00018a026

Liang W., Luo Z., Ge S., Li M., Du J., Yang M., Yan M., Ye Z. (2011): Oral administration of quercetin inhibits bone loss in rat model of diabetic osteopenia. Eur. J. Pharmacol. 670, 317-324 http://dx.doi.org/10.1016/j.ejphar.2011.08.014

Malstrom A., Carlstedt I., Aberg L., Fransson L. A. (1975): The copolymeric structure of dermatan sulphate produced by cultured human fibroblasts. Different distribution of iduronic acid and glucuronic acid-containing units in soluble and cell-associated glycans. Biochem. J. 151, 477-489

Mody N., Parhami F., Sarafian T. A., Demer L. L. (2001): Oxidative stress modulates osteoblastic differentiation of vascular and bone cells. Free Radic. Biol. Med. 31, 509-519 http://dx.doi.org/10.1016/S0891-5849(01)00610-4

Munoz M. C., Barbera A., Dominguez J., Fernandez-Alvarez J., Gomis R., Guinovart J. J. (2001): Effects of tungstate, a new potential oral antidiabetic agent, in Zucker diabetic fatty rats. Diabetes 50, 131-138 http://dx.doi.org/10.2337/diabetes.50.1.131

Nakhaee A., Bokaeian M., Akbarzadeh A., Hashemi M. (2010): Sodium tungstate attenuate oxidative stress in brain tissue of streptozotocin-induced diabetic rats. Biol. Trace Elem. Res. 136, 221-231 http://dx.doi.org/10.1007/s12011-009-8537-0

Ozdemir S., Tandogan B., Ulusu N. N., Turan B. (2009): Angiotensin II receptor blockage prevents diabetes-induced oxidative damage in rat heart. Folia Biol. (Praha) 55, 11-16

Partida-Hernandez G., Arreola F., Fenton B., Cabeza M., RomanRamos R., Revilla-Monsalve M. C. (2006): Effect of zinc replacement on lipids and lipoproteins in type 2-diabetic patients. Biomed. Pharmacother. 60, 161-168 http://dx.doi.org/10.1016/j.biopha.2006.02.004

Pieper G. M., Jordan M., Dondlinger L. A., Adams M. B., Roza A. M. (1995): Peroxidative stress in diabetic blood vessels. Reversal by pancreatic islet transplantation. Diabetes $44,884-889$ http://dx.doi.org/10.2337/diab.44.8.884

Reddy G. K., Stehno-Bittel L., Hamade S., Enwemeka C. S. (2001): The biomechanical integrity of bone in experimental diabetes. Diabetes Res. Clin. Pract. 54, 1-8 http://dx.doi.org/10.1016/S0168-8227(01)00273-X

Rodriguez-Gallardo J., Silvestre R. A., Egido E. M., Marco J. (2000): Effects of sodium tungstate on insulin and glucagon secretion in the perfused rat pancreas. Eur. J. Pharmacol. 402, 199-204 http://dx.doi.org/10.1016/S0014-2999(00)00492-1 
Rodriguez-Hernandez C. J., Guinovart J. J., Murguia J. R. (2012): Anti-diabetic and anti-obesity agent sodium tungstate enhances GCN pathway activation through Glc7p inhibition. FEBS Lett. 586, 270-276 http://dx.doi.org/10.1016/j.febslet.2011.12.035

Sachdeva S., Flora S. J. S. (2014): Efficacy of some antioxidants supplementation in reducing oxidative stress post sodium tungstate exposure in male wistar rats. J. Trace Elem. Med. Biol. 28, 233-239 http://dx.doi.org/10.1016/j.jtemb.2014.01.004

Seino Y., Ishida H. (1995): Diabetic osteopenia: pathophysiology and clinical aspects. Diabetes Metab. Rev. 11, 21-35 http://dx.doi.org/10.1002/dmr.5610110103

Silva M. J., Brodt M. D., Lynch M. A., McKenzie J. A., Tanouye K. M., Nyman J. S., Wang X. (2009): Type 1 diabetes in young rats leads to progressive trabecular bone loss, cessation of cortical bone growth, and diminished whole bone strength and fatigue life. J. Bone Miner. Res. 24, 1618-1627 http://dx.doi.org/10.1359/jbmr.090316

Silvestre R. A., Egido E. M., Hernandez R., Marco J. (2005): Tungstate stimulates insulin release and inhibits somatostatin output in the perfused rat pancreas. Eur. J. Pharmacol. 519, 127-134 http://dx.doi.org/10.1016/j.ejphar.2005.06.028

Trumbo P. R., Ellwood K. C. (2006): Chromium picolinate intake and risk of type 2 diabetes: an evidence-based review by the
United States Food and Drug Administration. Nutr. Rev. 64, 357-363 http://dx.doi.org/10.1111/j.1753-4887.2006.tb00220.x

Vasudevan H., McNeill J. H. (2007): Chronic cobalt treatment decreases hyperglycemia in streptozotocin-diabetic rats. Biometals 20, 129-134

http://dx.doi.org/10.1007/s10534-006-9020-4

Verhaeghe J., Suiker A. M., Einhorn T. A., Geusens P., Visser W. J., Van Herck E., Van Bree R., Magitsky S., Bouillon R. (1994): Brittle bones in spontaneously diabetic female rats cannot be predicted by bone mineral measurements: studies in diabetic and ovariectomized rats. J. Bone Miner. Res. 9, 1657-1667 http://dx.doi.org/10.1002/jbmr.5650091021

Wasowicz W., Neve J., Peretz A. (1993): Optimized steps in fluorometric determination of thiobarbituric acid-reactive substances in serum: importance of extraction $\mathrm{pH}$ and influence of sample preservation and storage. Clin. Chem. 39, 2522-2526

Zhen D., Chen Y., Tang X. (2010): Metformin reverses the deleterious effects of high glucose on osteoblast function. J. Diabetes Complications 24, 334-344 http://dx.doi.org/10.1016/j.jdiacomp.2009.05.002

Received: March 3, 2014

Final version accepted: June 27, 2014

First published online: July 17, 2014 